\title{
Efetividade do direito à educação na Jurisprudência do Tribunal de Justiça do Estado de São Paulo à Luz da Jurimetria
}

\author{
The effectiveness of the right to education in the São \\ Paulo State court of justice in the light of jurimetrics
}

\author{
Leandro SARAI \\ Universidade Presbiteriana Mackenzie (Mackenzie), \\ São Paulo/SP - Brasil \\ Daniel Francisco Nagao Menezes \\ Universidade Presbiteriana Mackenzie (Mackenzie), \\ São Paulo/SP - Brasil
}

Resumo O presente artigo, utilizando a jurimetria, busca estudar um conjunto de julgados do Tribunal de Justiça do Estado de São Paulo para apurar como o direito à educação vem sendo tratado pelo Judiciário paulista. Após levantamento de aspectos teóricos que demonstram uma tendência de reconhecer o direito à educação como um direito social fundamental de aplicação imediata e passível de exigibilidade judicial, questiona quais seriam as demandas submetidas ao Judiciário, quem seria o sujeito mais acionado e se a Justiça reconheceria esse direito. Os resultados indicam que direito a vagas, transporte, matrícula e idade mínima representam a maior parte da amostra. O Estado surge como o principal sujeito a ocupar o polo passivo das demandas. Por fim, constatou-se que em todos os casos analisados houve reconhecimento da exigibilidade do direito à educação e os resultados parecem apontar algo próximo a isso no que diz respeito ao acolhimento das pretensões colocadas, embora a última conclusão mereça ser confirmada pela ampliação da amostra.

Palavras-chave: Direito à educação. Direito Social. Efetividade. Exigibilidade. Jurimetria. 
Abstract This article, using jurimetrics, seeks to study a set of cases judged by the São Paulo State Court of Justice to determine how the right to education is being addressed by it. After lifting theoretical aspects that demonstrate a tendency to recognize the right to education as a fundamental social right of immediate application and legal enforceability, it asks what are the demands submitted to the Judiciary, who would be the defendant in the cases and if the Justice would recognize that right. The results indicate that the most cases are related to places in school, transportation, registration and minimum age to course the grade deserved. The state appears as the main subject to occupy the defendant demands. Finally, it was found that in all the cases analyzed there was recognition of the enforceability of the right to education, and the results seem to indicate something close to that with regard to the reception of the claims made, although this last conclusion deserves to be confirmed by larger sample.

Key-words: Right to education. Social Right. Effectiveness. EnforCEABILITY. JURIMETRICS.

\section{INTRODUÇÃO}

Tratar da efetividade do direito à educação exige, em primeiro lugar, uma abordagem teórica e do ordenamento jurídico a fim de delinear os elementos conceituais e as principais questões envolvidas.

Relativamente à efetividade desse direito, importa analisar dados da realidade com base nos referidos elementos teóricos, análise que será feita em um conjunto de julgados selecionados no Tribunal de Justiça do Estado de São Paulo versando sobre o direito à educação.

Esses julgados representam aquilo que emerge do confronto entre a atuação ou omissão do Estado no cumprimento de seus misteres e as demandas da sociedade que acabaram sendo submetidas ao Poder Judiciário.

O recorte é interessante, porque vai destacar quais expectativas sociais transparecem de modo efetivo em relação ao ordenamento posto, independentemente das normas que vêm sendo cumpridas e das que não vêm sendo cumpridas. 
Aplicando a jurimetria na amostra, o presente artigo procura verificar que aspectos do direito à educação geram litígios, e como tais demandas estão sendo solucionadas pelo Judiciário, além de confirmar se o Estado seria de fato o responsável pelo maior número de demandas.

\section{Aspectos teóricos e noRmativos}

Na Constituição Federal de 1988, o direito à educação é mencionado expressamente no artigo $6^{\circ}$., que compõe o Capítulo II, "Dos Direitos Sociais". Esse capítulo, por sua vez, integra o Título II, "Dos Direitos e Garantias Fundamentais", de modo que a própria configuração topográfica indica que o direito à educação seria um direito fundamental.

É certo que o próprio artigo $6^{\circ}$. estabelece que esses direitos o são na "forma desta Constituição." Porém, o texto constitucional trouxe extensa normatização do direito à educação entre os artigos 205 a 214, bem como, em outras disposições espalhadas pela Constituição. ${ }^{1}$ Ele distribui entre os entes políticos os níveis de educação a que devem dedicar-se e prevê montantes mínimos percentuais de recursos a serem aplicados, além de arrolar princípios para o ensino, entre os quais a garantia de padrão de qualidade.

A previsão de padrão de qualidade remete ao princípio da eficiência, previsto no caput do artigo 37 da Constituição Federal, que afeta toda a Administração Pública. Essa exigência é importante na medida em que, associando exigência de qualidade e de eficiência, o ente público não pode pretender alcançar os objetivos constitucionais apenas por meio da exigência de mais recursos públicos. É inegável que o ingresso de recursos suficientes para a prestação do serviço público não pode ser descurado, mas tão importante quanto os recursos é a exigência da contrapartida, da entrega de resultados, de modo a valorizar o emprego desses escassos recursos.

1 Tanto a palavra ensino quanto a palavra "educação" aparecem aproximadamente 50 vezes no texto. 
Feitos esses apontamentos introdutórios, segundo os quais, de acordo com a literalidade dos termos da Constituição, haveria uma indicação de que o direito à educação seria um direito social fundamental, cabe agora trazer algumas considerações doutrinárias sobre ele.

Direitos sociais, nas palavras de Manoel Gonçalves Ferreira Filho (2010, p. 342), "são direitos a prestações positivas por parte do Estado, vistos como necessários para o estabelecimento de condições mínimas de vida digna para todos os seres humanos".

Na doutrina, pois, também se encontra o direito à educação tido como direito fundamental (FERREIRA FILHO, 2009, p. 305-306; DUARTE, 2007), mas o que isso implica e a que questões essa premissa leva?

Embora tendo como foco a Constituição de Portugal, Cristina Queiroz (2005, p. 198-199) apresenta entendimentos da doutrina segundo os quais os direitos sociais não seriam meras promessas. Primeiro, porque serviriam de parâmetro para o controle judicial dos atos do Poder Público que os contrariem, além de diretriz interpretativa na realização desses direitos. Em segundo lugar, poderiam levar à configuração de uma inconstitucionalidade por omissão decorrente da inércia do Estado. Por fim, proibiriam a supressão dos direitos já concretizados, ou seja, o retrocesso social. Mas a autora parece sustentar que, além disso e apesar das controvérsias a respeito, haveria um "status activus processualis" (QUEIROZ, 2005, p. 216), permitindo a tutela jurisdicional efetiva desses direitos "sem que caiba atribuir a nenhum dos direitos constitucionais implicados um significado puramente declarativo ou programático" (QUEIROZ, 2005, p. 216).

Parte da concepção da autora é claramente ancorada na lição de José Joaquim Gomes Canotilho (1995, p. 545 e 667), segundo o qual existe uma "verdadeira imposição constitucional, legitimadora, entre outras coisas, de transformações económicas e sociais, na medida em que estas forem necessárias para a efectivação desses direitos".

No Brasil, Manoel Gonçalves Ferreira Filho (2009, p. 298-299) questiona, a propósito, se o aumento na quantidade de direitos fundamentais não levaria a uma diminuição de sua importância, fenômeno 
semelhante ao que ocorreria com o valor de uma moeda, que decairia com a emissão de mais moeda. Além disso, esse aumento também conduziria ao questionamento do alcance da expressão "fundamental", que tenderia a tornar-se sinônimo de "importante", caso se considerasse efetivamente todos os direitos como fundamentais. Quanto a isso, referido autor (2009, p. 301-302) sustenta que haveria sim um conjunto principal de direitos, ou seja, um núcleo fundamental no âmbito dos direitos fundamentais, estando os demais direitos figurando como direitos satélites ou secundários.

Implicação relevante decorrente do fato de o direito à educação ser um direito fundamental estaria no debate acerca de sua exigibilidade perante o Estado. Manoel Gonçalves Ferreira Filho (2009, p. 254) menciona a existência de decisões judiciais garantindo esse direito, por exemplo, com a abertura de vagas em escolas, decisões que, segundo ele, estariam de acordo com a inafastabilidade da apreciação do Poder Judicial sobre lesões ou ameaças a direitos, bem como com a aplicabilidade imediata das normas definidoras de direitos e garantias fundamentais, de acordo com o disposto respectivamente no inciso XXXV e no $\S 1^{\circ}$. do artigo $5^{\circ}$. da Constituição brasileira.

Esse posicionamento do Judiciário não seria um ativismo judicial, mas decorreria, nas palavras dele, da própria Constituição, que impõe princípios e regras a serem observados (FERREIRA FILHO, 2009, p. 256). Como isso poderia levar a uma politização da justiça, conforme ressalta o mesmo autor (2009, p. 257-258), caberia analisar se o regime de governo no Brasil não seria, então, misto, com o Executivo e o Legislativo de fonte democrática e o Judiciário aristocrático.

Clarice Seixas Duarte (2004) também demonstra que a exigibilidade judicial decorre da norma constitucional, inclusive com sustentação na evolução histórica dos direitos sociais.

José Afonso de Silva (2012, p. 187) expressamente sustenta a aplicabilidade imediata desse direito. Para esse autor, seria um direito público subjetivo ou, em outras palavras, um direito plenamente eficaz e exigível judicialmente. Ele (SILVA, 2012, p. 800) transcreve passagem de Anísio Teixeira, onde fica nítida a relevância desse direito principal- 
mente para as classes despossuídas, como forma de buscar melhores condições. ${ }^{2}$

Em se tratando de exigibilidade e tendo em conta que, de acordo com o artigo 205 da Constituição Federal, haveria dever por parte não só do Estado, mas também da família, com promoção e incentivo com a colaboração da sociedade, não se afasta a possibilidade de questionamento do que poderia ser exigido dos particulares, e em que medida, mormente quando se atribui natureza de serviço de utilidade pública à educação (GOMES, 2009).

Ainda que considerado importante e mesmo que se admita a exigibilidade da prestação do serviço de educação, cabe trazer novamente o aspecto relacionado com os recursos necessários para tanto. Especificamente sobre a exigibilidade de aplicação de percentual mínimo do orçamento em educação, não se vê maiores problemas.

Com efeito, a Constituição Federal é expressa no artigo 212, por exemplo, ao determinar a aplicação pela União de no mínimo $18 \%$ da receita resultante de impostos. Não é difícil calcular quanto representariam esses $18 \%$ em relação à receita e determinar a comprovação da aplicação desse importe. Os problemas começam quando se depara com a natureza dos gastos que podem ser considerados como necessários ao adimplemento da obrigação constitucional de educar.

A título de ilustração, a Lei n ${ }^{0}$. 11.494, de 20 de junho de 2007, que regulamenta o Fundo de Manutenção e Desenvolvimento da Educação Básica e de Valorização dos Profissionais da Educação - FUNDEB, deixa claro em seu artigo 22 que os recursos podem ser usados para re-

2 Diz Anísio Teixeira, citado por José Afonso da Silva: “Obrigatória, gratuita e universal, a educação só poderia ser ministrada pelo Estado. Impossível deixá-la confiada a particulares, pois estes somente podiam oferecê-la aos que tivessem posses (ou a 'protegidos'), e daí operar antes para perpetuar as desigualdades sociais, que para removê-las. A escola pública, comum a todos, não seria, assim, o instrumento de benevolência de uma classe dominante, tomada de generosidade ou de medo, mas um direito do povo, sobretudo das classes trabalhadoras, para que, na ordem capitalista, o trabalho (não se trata, com efeito, de nenhuma doutrina socialista, mas do melhor Capitalismo) não se conservasse servil, submetido e degradado, mas igual ao capital na consciência de suas reivindicações e dos seus direitos". 
munerar profissionais do magistério da educação básica. Em seu artigo 23 , por sua vez, indica aplicações vedadas, conforme o artigo 71 da Lei $n^{\circ}$. 9.394, de 20 de dezembro de 1996.

A Lei ${ }^{\circ} .9 .394$, de 20 de dezembro de 1996, que estabelece as diretrizes e bases da educação nacional, dispõe em seu artigo 71 quais gastos não seriam considerados como destinados à manutenção e desenvolvimento do ensino, estando entre eles, por exemplo, pagamento de professores quando em desvio de função ou em atividade alheia à manutenção e desenvolvimento do ensino.

Por sua vez, o artigo $4^{\circ}$. dessa Lei descreve quais atividades estariam abrangidas pelo dever do Estado com a educação escolar pública. Nele se encontra, por exemplo, o "atendimento ao educando, em todas as etapas da educação básica, por meio de programas suplementares de material didático-escolar, transporte, alimentação e assistência à saúde".

Esses detalhamentos ajudam e são desejáveis, embora, no limite, poderá haver alguma margem de dúvida. Afinal, qual seria o conteúdo a ser ensinado? Quantas horas de estudo? Qual a quantidade de alunos por sala de aula? Deveriam ser incluídos no currículo assuntos como cidadania, conduta ética, respeito ao próximo, cuidados com a cidade e com as coisas coletivas, dever de avisar o Poder Público quando se constata algum problema com o patrimônio coletivo ou alguma infração legal, dever de fiscalizar o Poder Público?

Também existe o problema daqueles casos em que seja indiscutível o dever do Estado de realizar determinada atividade, dever que, pelo detalhamento do ordenamento jurídico, seja plenamente exigível, ainda que por meio da intervenção do Poder Judiciário, mas que possa ser impossível cumprir sem que outro dever igualmente exigível seja prejudicado. Para ilustrar, basta imaginar que haja recursos suficientes apenas para um de dois serviços a serem prestados.

Em situações como essa, caberia dividir os recursos? Qual deveria ser a prioridade? Poderia o Judiciário decidir a prioridade, ainda que esta não esteja prevista no ordenamento jurídico?

Tendo em conta apenas o direito à educação, Clarice Seixas Duarte (2007, p. 699-700) lembra que, de acordo com o Pacto Interna- 
cional dos Direitos Econômicos, Sociais e Culturais, direitos como ele deveriam ser realizados progressivamente, ainda que não em um curto espaço de tempo. Além disso, o Estado teria que adotar "medidas até o máximo de seus recursos disponíveis" e não retroceder em relação ao que já houvesse concretizado (DUARTE, 2007, p. 699-700).

Importante ainda é a necessidade de demonstração do Estado de que "empenhou todos os esforços para utilizar os recursos disponíveis” em relação às obrigações mínimas essenciais (DUARTE, 2007, p. 699-700).

$\mathrm{Na}$ mesma linha, Emerson Garcia (2007, p. 116) defende que o direito à educação estaria incluído no mínimo existencial em norma de eficácia plena e aplicabilidade imediata passível de exigibilidade judicial, ressalvada apenas a comprovação pelo Poder Público de que efetivamente não haveria recursos para tanto.

Além do aspecto da exigibilidade do direito perante o Estado, é importante aferir como ele vem cumprindo o que dele se espera. Analisando dados estatísticos, Romualdo Portela de Oliveira (2007) demonstra, sob a perspectiva histórica, como o Brasil vem conseguindo efetivamente ampliar o acesso à educação em busca de atingir seu ideal de universalização. Não descura, contudo, do fato de que paralelamente a esse fenômeno se ergue o desafio da qualidade do ensino.

Também ressalta esse fato Marta Arretche (2012, p. 168), para quem o Fundef teria possibilitado a expansão das matrículas no ensino fundamental e o aumento dos salários dos professores, mas sem haver melhoria na proficiência relativa dos alunos das escolas públicas. Dirce Nei Teixeira de Freitas (2008) também salienta que apesar da evolução, ainda se está distante do atingimento de níveis ideais de qualidade.

E se a qualidade do ensino é questionada, entra em cena a avaliação como instrumento que busca medir objetivamente esse aspecto, como destaca Magno Federici Gomes (2009, p. 271-272), embora em artigo específico sobre o ensino superior.

As avaliações são instrumentos importantes na busca de retratar de forma objetiva os resultados das políticas públicas, permitindo comparação e verificação de acertos e erros nas decisões tomadas. A títu- 
lo de exemplo, Marilene Zampiri e Ângelo R. Souza (2014), com base nos resultados do IDEB relativo ao município de Curitiba, conseguiram apurar que a atuação de forma não prioritária em certos níveis de ensino provoca instabilidade e heterogeneidade no aprendizado dos alunos. Assim, para fins de esclarecimento, se o município atua prioritariamente no ensino fundamental e de forma subsidiária no ensino médio, a qualidade do aprendizado dos alunos deste tende a ser muito heterogênea.

Aqui se insere não só a avaliação das instituições de ensino, mas também a avaliação dos alunos e a forma como ela deve ser. Márcia Aparecida Jacomini (2014), por exemplo, retrata a progressão continuada como forma de democratizar o ensino, que exigiria maior empenho da escola para tratar aqueles alunos que, antes, eram simplesmente excluídos pela reprovação.

Ainda no texto de Marta Arretche (2012, p. 166), a efetividade do direito à educação, especificamente em relação ao ensino fundamental, é fortemente influenciada pela capacidade financeira de cada ente. Como o ensino fundamental é de responsabilidade de Estados e municípios, varia muito a participação de cada ente na expansão das matrículas, assim como há grande desigualdade horizontal e vertical na capacidade de gastos e, por conseguinte, nos salários de professores e na qualidade do ensino.

Esse aspecto apareceu em análise de decisões judiciais relativas ao direito à educação no Supremo Tribunal Federal e no Tribunal de Justiça do Estado de São Paulo, onde Adriana Dragone Silveira (2013, p. 373) levantou que são utilizados contrariamente à concretização do direito à educação argumentos como: "escassez de recursos; impossibilidade de interferência do Judiciário no poder discricionário do Executivo"; e questões relativas ao planejamento e concretização de políticas públicas.

Embora ações coletivas tendam a tornar mais igualitária a distribuição de benefícios, as decisões do TJ-SP demonstrariam que haveria mais facilidade de acolhimento do pedido em ações individuais do que em ações coletivas. Nas coletivas, acabava prevalecendo o argumento de que não se poderia interferir na condução das políticas públicas (SILVEIRA, 2013, p. 376; 382-383). 
Trazendo os argumentos de algumas decisões, percebe-se que, quanto à reserva do possível, o Judiciário chegou a afirmar que ela deve estar ligada a um justo motivo demonstrado objetivamente. Além disso, considerou não caber a alegação de falta de recursos quando há dolosa manipulação do orçamento para acarretar a insuficiência financeira (SILVEIRA, 2013, p. 378-379).

No que diz respeito ao argumento da impossibilidade de interferência do Judiciário e eventual ofensa ao princípio da separação dos poderes, Adriana Dragone Silveira (2013, p. 380-382) apresenta doutrina que, de forma coerente, esclarece não haver essa ofensa quando se está diante de evidente omissão ilegal.

Acerca da questão do conflito entre demandas individuais e coletivas, cabe arrolar os aspectos levantados por Adriana Dragone Silveira (2013, p. 382-383). De um lado, as demandas coletivas, como dito, seriam instrumentos mais propícios a uma justa distribuição de benefícios, uma vez que a demanda individual acaba fazendo o indivíduo "passar na frente na fila". De outro lado, se se trata de um direito a que inúmeros cidadãos já têm acesso, talvez a demanda individual seja adequada por sanar a omissão relativa àquele indivíduo, caso em que a injustiça estaria precisamente nessa omissão.

Dois problemas aparecem ainda nas demandas coletivas. Um problema que surge ligado à compatibilidade desses instrumentos coletivos com o planejamento do orçamento público. Para esse problema, o ideal seria que ambos caminhassem juntos, ou seja, a ação coletiva seria instrumento de expressão da demanda social que deveria ser atendida por meio do orçamento. Outro problema estaria no fato de o Judiciário não estar preparado para demandas coletivas, de modo que o principal obstáculo ao sucesso das demandas estaria, dessa forma, na própria Justiça e no argumento da ofensa à separação dos poderes (SILVEIRA, 2013, p. 383-384).

De todo modo, é importante ressaltar que, se, de um lado, as comunidades mais carentes seriam, em tese, as mais prejudicadas quanto ao atendimento de seus direitos, de outro lado, seriam também, em tese, as que menos teriam acesso à Justiça. Daí a importância de o Estado, 
por meio de suas instituições, promover a integração desses cidadãos aos seus direitos por intermédio, entre outros instrumentos, das demandas coletivas (SILVEIRA, 2010a; PAROSKI, 2006, p. 225-242).

Outro trabalho de Adriana Dragone Silveira que merece ser mencionado é sua tese de doutorado que apurou a efetividade do direito à educação na jurisprudência do Tribunal de Justiça, considerando o período de 1991 a 2008 (SILVEIRA, 2010b). Segundo ela (2010b, p. 214):

Das decisões proferidas pelo TJ-SP, envolvendo direitos educacionais, pode-se inferir que em algumas demandas consolidou-se uma jurisprudência favorável à exigibilidade por meio do Judiciário, determinando que o Executivo cumprisse com suas atribuições. Por outro lado, persiste uma tendência, ainda que minoritária no TJ-SP, de recorrer ao argumento central da impossibilidade de o Judiciário intervir em atos que sejam da esfera exclusiva do Executivo, tendência, essa, prevalente em demandas concentradas na deliberação política.

Nesse mesmo trabalho, Adriana Silveira (2010b, p. 221) também constatou que houve maior sucesso nas demandas individuais do que nas coletivas.

\section{Dados e problematizaÇão}

Com o apanhado teórico e normativo colocado até aqui, já é possível vislumbrar algumas questões que envolvem o tema. Antes, contudo, de formular os problemas da presente pesquisa e as respectivas hipóteses, cabe a citação de alguns dados.

Segundo o Instituto Nacional de Estudos e Pesquisas Educacionais-INEP, em 1998, o contingente de alunos incluindo todos os níveis de ensino e o ensino profissional ultrapassava 55 milhões e era o quarto maior do mundo, atrás de China, Índia e Estados Unidos (INSTITUTO NACIONAL DE ESTUDOS E PESQUISAS EDUCACIONAIS, 2000, p. 11). Embora não se possa esquecer da análise de quanto esse montan- 
te representa em relação ao total da população do país, esses números absolutos servem para evidenciar a responsabilidade que pesa sobre o Estado e sobre a sociedade e as repercussões que essas decisões podem ter. Apenas para ilustrar, conforme a decisão tomada, se ela implicar um gasto, esse gasto eventualmente pode ter que ser, em tese, multiplicado, no limite, por 55 milhões. Atualmente, passados mais de 15 anos, é muito provável que esse número já esteja bem maior.

A propósito da necessidade de se pensar o montante de alunos com relação à população em idade escolar, esse mesmo estudo do INEP (2000, p. 12) indica que $95 \%$ das crianças com faixa etária entre 7 e 14 anos e $81 \%$ dos adolescentes de 15 a 17 anos estavam na escola, sendo que as matrículas no ensino médio vinham se expandindo desde 1990 a uma taxa média de $10 \%$ e no ensino superior a uma taxa média de $7 \%$ ao ano.

Na referida publicação (2000, p. 16), colocava-se como desafio elevar os gastos públicos com a educação de 5\% para 6,5\% do PIB em um período de 10 anos.

Na comparação de alguns desses dados com o que se observa em 2010, alguma evolução pode ser notada. Segundo o IBGE, em 2010, $96,7 \%$ da população de 6 a 14 anos de idade frequentavam a escola. Além do aumento percentual, percebe-se que esse montante considera também a população com 6 anos de idade, o que o torna ainda mais significativo. Em relação à faixa etária de 15 a 17 anos, o IBGE diz que $16,7 \%$ não frequentavam a escola. Embora isso possa significar que $83,3 \%$ frequentavam a escola, de modo que também haveria evolução nesse grupo (INSTITUTO BRASILEIRO DE GEOGRAFIA E ESTATÍSTICA, 2010, p. 54), também se deve considerar que, desses 83,3\%, apenas $47,3 \%$ estavam no ensino médio, conforme demonstra a mesma publicação (2010, p. 72).

Outro dado importante a considerar, oferecido pela mesma fonte (2010, p. 78), diz respeito ao fato de ter caído a população com 25 anos ou mais de idade sem instrução ou com ensino fundamental incompleto, entre os anos de 2000 e 2010 , de $58 \%$ para $44,2 \%$ na área urbana e de $90,3 \%$ para $79,6 \%$ na área rural.

Com relação ao desafio do aumento do gasto público com a educação, há uma tabela do INEP que mostra uma evolução da estimativa do 
percentual do investimento direto em educação por esfera de governo em relação ao PIB, saindo de 3,9\% em 2000 e atingindo 5\% em 2009 (INSTITUTO NACIONAL DE ESTUDOS E PESQUISAS EDUCACIONAIS, 2011). Embora ela demonstre essa evolução, não é possível comparar essa tabela com o desafio colocado de elevar o gasto de 5\% para $6,5 \%$ do PIB, pois esses percentuais parecem ter utilizado bases e critérios distintos.

Os dados apresentados até aqui mostram evoluções quantitativas, mas, diante dos apontamentos teóricos colocados no tópico anterior, não revelam como esses avanços se refletem nas demandas sociais, ou seja, apesar dos aumentos percentuais, não se evidencia o que a sociedade vem pleiteando do Estado.

Os principais problemas da pesquisa, então, dizem respeito ao que estaria sendo pleiteado, de quem e como estariam sendo tratados.

$\mathrm{O}$ primeiro diria respeito à natureza das pretensões, se ligadas a vagas, transporte, alimentação etc.

O segundo, em razão do aspecto teórico que aponta a aplicabilidade dos direitos sociais também na relação entre particulares.

O terceiro, para verificar se a exigibilidade tem sido aceita e também se tem sido atendida.

Colocados de forma interrogativa:

a) Quais as demandas relacionadas à educação e o montante percentual de cada uma no total?

b) Quem seria o sujeito mais acionado na justiça, o Poder Público ou os particulares?

c) A Justiça estaria atendendo aos pleitos?

Como hipóteses da pesquisa, para cada um dos problemas:

a) O maior pleito, em tese, seria o de vagas.

b) Apesar da existência de escolas particulares, seria o Estado, em tese, o sujeito mais acionado.

c) As demandas, em tese, vêm sendo aceitas.

Para validar essas hipóteses, a pesquisa caminhará agora para um recorte das decisões proferidas pelo Tribunal de Justiça do Estado de São Paulo, por meio de consulta ao Portal desse órgão na internet. 
A metodologia empregada segue descrita, justificando os critérios e recortes efetuados.

\section{Metodologia e Justificativa}

Utilizando a técnica da jurimetria (BARBOSA; MENEZES, 2013, p. 160-185), o presente artigo procurará analisar julgados do Tribunal de Justiça do Estado de São Paulo, a partir da coleta de dados por meio de pesquisa realizada no portal desse Tribunal na internet em $1^{\circ} . / 3 / 2015 .^{3}$

Os critérios utilizados na pesquisa e os resultados gerados estão detalhados na tabela única a seguir:

Tabela única - Número de julgados em percentuais

\begin{tabular}{l|r|r}
\hline \multicolumn{1}{c|}{ Assunto } & $\begin{array}{c}\text { Número de } \\
\text { casos }\end{array}$ & $\%$ \\
\hline Matrícula & 18 & $12,68 \%$ \\
\hline Vaga & 17 & $11,97 \%$ \\
\hline Idade mínima para a série de ensino & 16 & $11,27 \%$ \\
\hline Transporte & 16 & $11,27 \%$ \\
\hline Vaga em creche & 15 & $10,56 \%$ \\
\hline Contratação de professor especial & 9 & $6,34 \%$ \\
\hline $\begin{array}{l}\text { Garantia de pensão por morte até completar } \\
\text { estudos }\end{array}$ & 8 & $5,63 \%$ \\
\hline Vaga para aluno especial & 7 & $4,93 \%$ \\
\hline Retenção de documento para forçar o paga- & 5 & $3,52 \%$ \\
mento & & \\
\hline Acessibilidade de edificação & 4 & $2,82 \%$ \\
\hline Vaga próxima & 4 & $2,82 \%$ \\
\hline
\end{tabular}

3 Disponível em: <https://esaj.tjsp.jus.br/cjsg/consultaCompleta.do?f=1 > Acesso em: 25/2/2015. 


\begin{tabular}{|c|c|c|}
\hline Assunto & $\begin{array}{l}\text { Número de } \\
\text { casos }\end{array}$ & $\%$ \\
\hline $\begin{array}{l}\text { Vaga e transporte de alunos com necessida- } \\
\text { des especiais }\end{array}$ & 3 & $2,11 \%$ \\
\hline $\begin{array}{l}\text { Exigência de funcionamento ininterrupto da } \\
\text { escola }\end{array}$ & 2 & $1,41 \%$ \\
\hline Transferência compulsória & 2 & $1,41 \%$ \\
\hline Bolsa de estudos & 1 & $0,70 \%$ \\
\hline Escolha de escola & 1 & $0,70 \%$ \\
\hline Concessão de crédito FIES & 1 & $0,70 \%$ \\
\hline Troca de horário do período de aulas & 1 & $0,70 \%$ \\
\hline Horário especial de aluno servidor público & 1 & $0,70 \%$ \\
\hline Escolha de horário de aulas & 1 & $0,70 \%$ \\
\hline Custeio de vestibular & 1 & $0,70 \%$ \\
\hline Reprovação por faltas em universidade & 1 & $0,70 \%$ \\
\hline $\begin{array}{l}\text { Recomposição de classes feita com base na } \\
\text { Resolução SE } 169 / 96\end{array}$ & 1 & $0,70 \%$ \\
\hline $\begin{array}{l}\text { Respeito ao credo religioso para faltar às } \\
\text { sextas à noite }\end{array}$ & 1 & $0,70 \%$ \\
\hline $\begin{array}{l}\text { Agrupamentos de alunos de séries distintas } \\
\text { na mesma classe }\end{array}$ & 1 & $0,70 \%$ \\
\hline Vaga em creche próxima & 1 & $0,70 \%$ \\
\hline Vaga em escola técnica & 1 & $0,70 \%$ \\
\hline Vaga por remoção de ofício de servidor & 1 & $0,70 \%$ \\
\hline Vaga e transporte & 1 & $0,70 \%$ \\
\hline Vaga para bolsista & 1 & $0,70 \%$ \\
\hline Total & 142 & $100,00 \%$ \\
\hline
\end{tabular}

Fonte: Tabela elaborada pelo autor com dados do Portal do Tribunal de Justiça do Estado de São Paulo

Com relação ao aspecto temporal, não houve restrição do período pesquisado, uma vez que, com a utilização do critério "direito à educação", foram retornados 182 resultados no total, número considerado passível de estudo no prazo disponível para a elaboração do presente artigo. 
Após excluir os agravos e embargos de declaração, para se evitar duplicidades, bem como os casos que envolviam conflitos de competência para se julgar o tema, chegou-se ao número de 142 julgados.

Apesar de não se ter feito uma limitação temporal nos critérios de pesquisa, verificou-se que o julgado mais antigo encontrado é de 1998 (ESTADO DE SÃO PAULO, 1998). Isso não significa necessariamente que antes dessa data não tenha havido demanda. É provável que se trate da data em que os dados começaram a ser cadastrados no sistema de pesquisa. Tanto é que Adriana Silveira (2010b), por exemplo, levantou demandas desde 1991.

Ainda no trabalho de Silveira (2010b, p. 102), nota-se que as demandas mais comuns, segundo sua classificação seriam: acesso à educação básica ( 284 casos ou $58,6 \%$ do total), poder de regulação estatal (67), permanência (36), decisões administrativas e políticas (36), responsabilidade estatal (35), gestão dos recursos públicos (14) e deveres dos pais (11), conforme gráfico a seguir, elaborado pelo autor com base nos dados de Silveira:

Gráfico 1 - Tipos de demandas e participação percentual

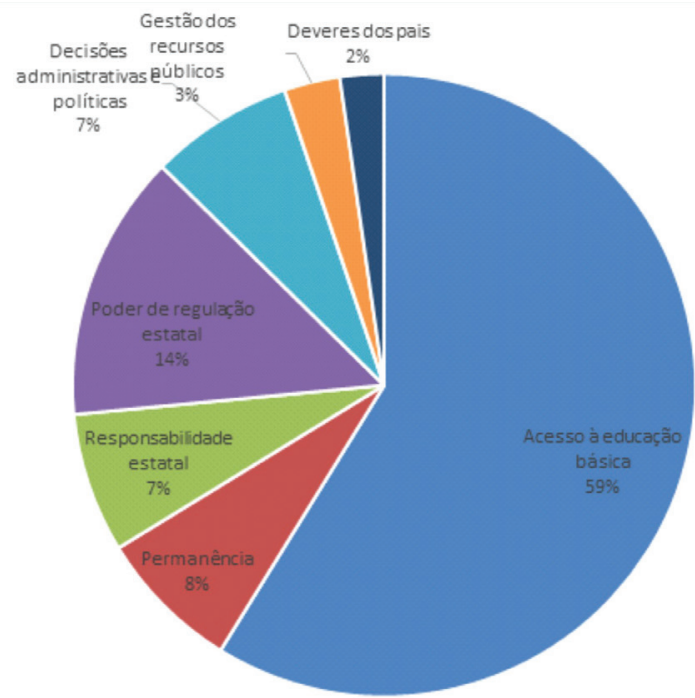

Fonte: Elaborado pelo autor com base nos dados de Silveira (2010b, p. 102) 
Entre as demandas buscando acesso à educação, a procura de vagas na educação infantil respondia por 175 casos, seguida pela procura no ensino fundamental com 73 casos (SILVEIRA, 2010b, p. 103):

Gráfico 2 - Classificação e participação das demandas de acesso à educação:

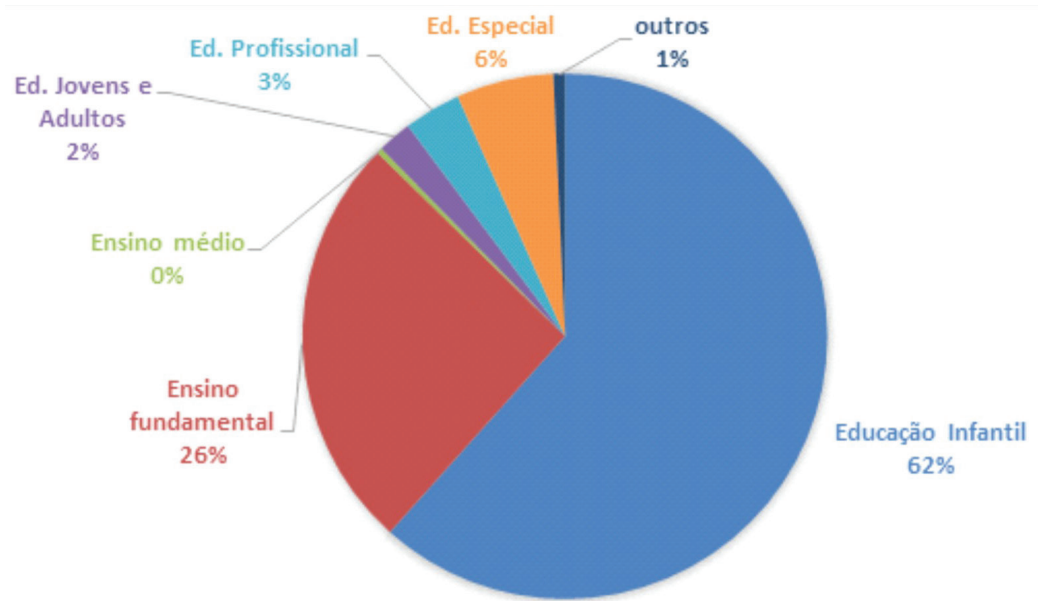

Fonte: Elaborado pelo autor com base nos dados de Silveira (2010b, p. 103)

Como justificativa para o presente trabalho, cabe destacar que o levantamento aqui feito é mais atual, uma vez que o trabalho de Adriana Silveira considerou os julgados até 2008, enquanto aqui se levou em conta até março de 2015.

Assim, busca-se de certa forma atualizar a visão sobre a jurisprudência do TJ/SP.

A pesquisa levou em conta apenas julgados que contivessem os critérios selecionados no campo "ementa". Com isso, obviamente, ficaram de fora os julgados que não tenham sido incluídos no banco de dados ou que, apesar de incluídos, não apresentem os termos de busca no campo ementa.

Deve-se acrescer o fato de que a ausência da demanda no Tribunal não significa que ela não exista na sociedade. Apenas demonstra que ela não chegou à Justiça. Por sua vez, se efetivamente há um suposto grau 
de dificuldade de acesso à Justiça, a presença de demandas no Tribunal pode indicar que elas seriam efetivamente importantes, pois o interessado teria superado referida dificuldade ou considerado mais benéfico se socorrer da Justiça num cálculo de custos e benefícios.

\section{Análise dos dados e discussão}

Conforme já apontado, foram selecionados 142 julgados. Esse resultado decorreu de pesquisa efetuada com a expressão "direito à educação" no campo "ementa" e exclusão dos agravos, embargos de declaração e conflitos de competência. Ainda que possível a existência de outros julgados sobre o assunto que não constem do resultado, não se nega que, se o direito à educação foi importante para orientar a decisão, a expressão deveria constar da ementa.

Como o julgado mais antigo é de 1998, o número de julgados encontrados no período de 1998 até 2015 se mostra muito reduzido, tendo em conta a população do Estado de São Paulo, de aproximadamente 45 milhões de pessoas (INSTITUTO BRASILEIRO DE GEOGRAFIA E ESTATÍSTICA, 2016). Esse número, em tese, poderia estar ligado também ao fato de o maior número populacional do Estado gerar maior número total de processos, tornando mais lento o julgamento de cada causa singularmente considerada. O número reduzido também poderia, em tese, representar eventual satisfação da população quanto ao serviço prestado, embora essa satisfação deva estar apoiada em critérios de julgamento de cada indivíduo. Essas hipóteses ficam aqui em aberto, por não serem o problema principal da pesquisa.

Como o primeiro problema colocado diz respeito à natureza das demandas, é importante citar que, dos 142 casos selecionados, 22 são ações civis públicas, representando $15,49 \%$ : 
Gráfico 3 - Participação de ações individuais e coletivas:

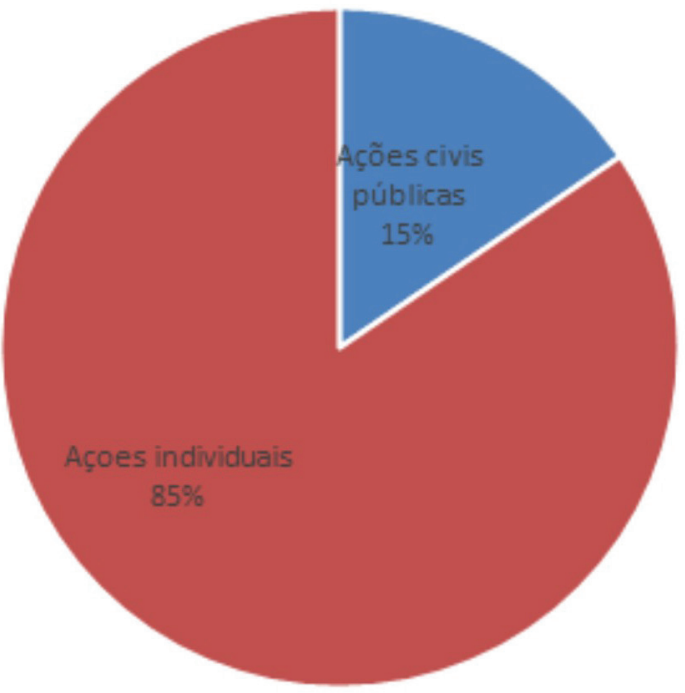

Fonte: Elaborado pelo autor

É notório que o número populacional é maior do que o número de organizações legitimadas para o ajuizamento das ações coletivas, o que pode explicar o menor percentual das ações civis públicas no total.

Feito esse introito, pode-se passar para o primeiro problema da pesquisa.

$\mathrm{Na}$ análise dos julgados, foram encontrados os assuntos agrupados na tabela única citada, com os respectivos percentuais de participação, podendo ser melhor visualizados no gráfico 4 .

Se os assuntos mais expressivos tratados na tabela única forem reunidos, será possível verificar que a demanda por vagas representa $35,92 \%$ dos casos, a de transporte $14,08 \%$, a de matrícula $12,68 \%$ e o questionamento da exigência de idade mínima para cursar a série pretendida responde por $11,27 \%$ dos casos: 


\section{Gráfico 4 - Tipos de demandas e participação:}

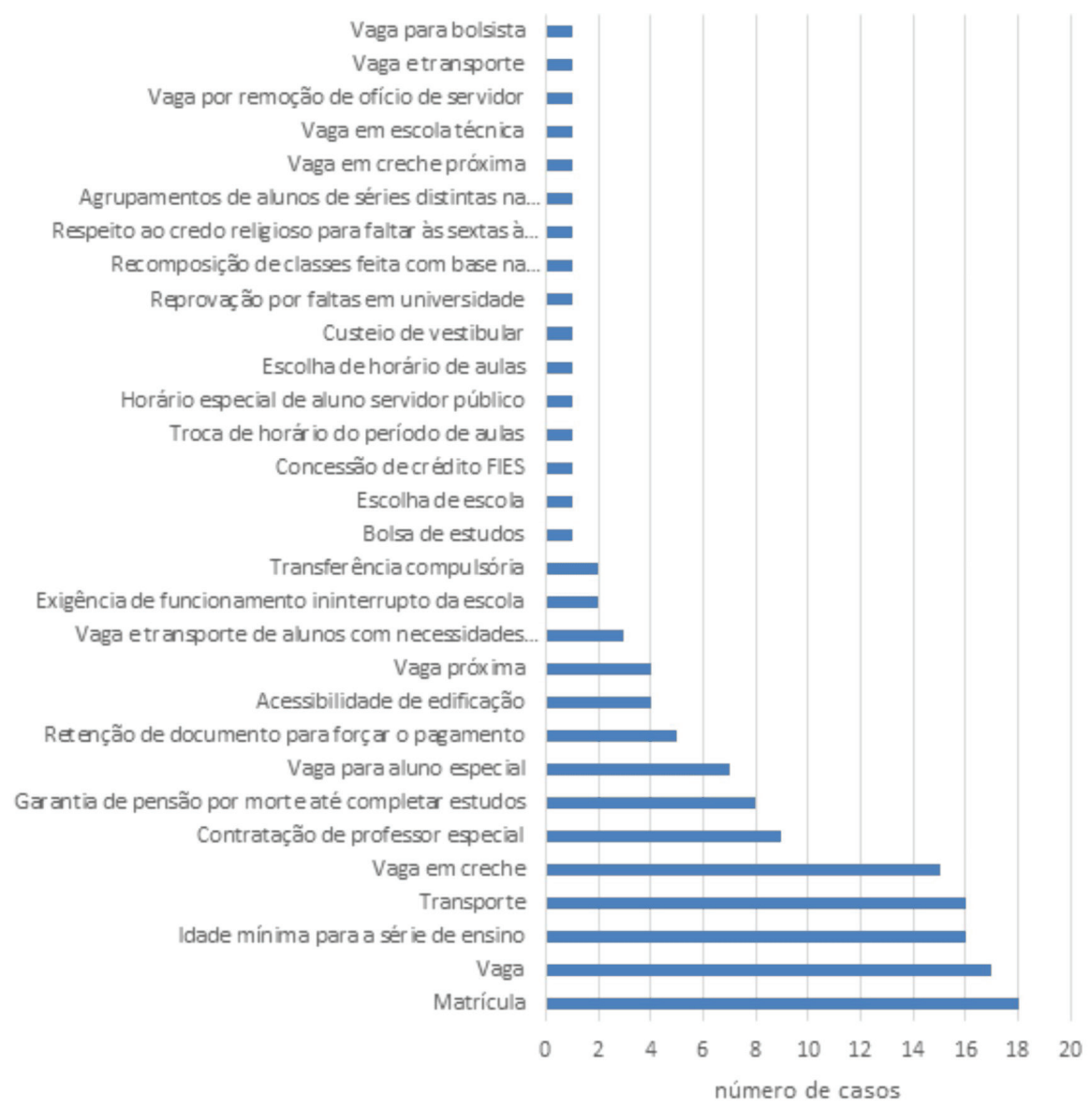

Fonte: Elaborado pelo autor 
Gráfico 5 - Casos mais frequentes agrupados:

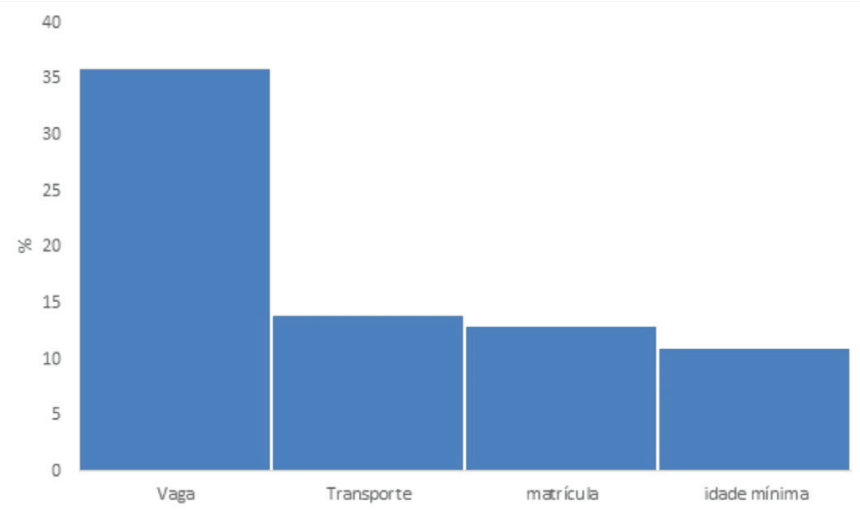

Fonte: Elaborado pelo autor

Percebe-se, com isso, que a hipótese se confirmou, fato que talvez justifique nas publicações oficiais citadas a preocupação que há com o aspecto do percentual de atendimento.

Quanto ao problema do sujeito mais acionado na Justiça, do total de 142 casos, apenas 14 foram promovidos em face de particulares, representando o importe de $9,86 \%$ :

Gráfico 6 - Participação do Estado e de particulares no polo passivo:

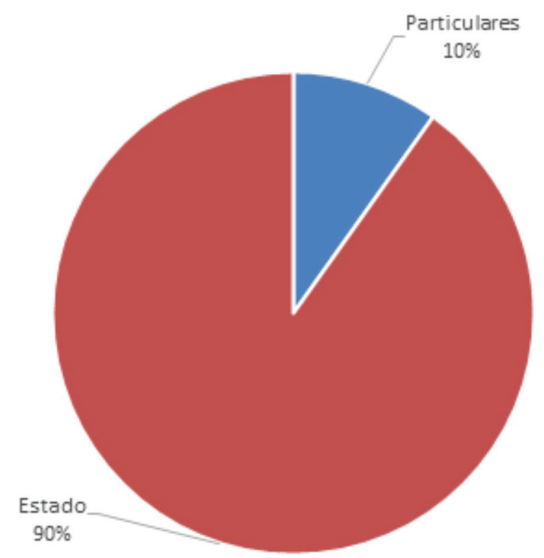

Fonte: Elaborado pelo autor 
Confirma-se, assim, a tese de que o Estado seria o principal réu nas ações envolvendo direito à educação, talvez até por conta de manter maior número de relações intersubjetivas do que qualquer instituição particular.

O último problema da pesquisa dizia respeito ao reconhecimento da exigibilidade dos direitos e ao grau de sucesso das demandas. Aqui aparece o resultado mais impressionante.

Dos 142 casos, apenas 11 foram desfavoráveis. Porém, olhando de perto cada caso em que o pedido não foi acolhido, percebe-se que o direito à educação praticamente não foi negado em nenhum deles, conforme síntese dos casos feita a seguir:

a) Foi negado o direito de escolher a escola, mas não a vaga;

b) Foi negado o direito de matrícula em escola particular por aluno inadimplente;

c) Foi reconhecida a regularidade da extinção da pensão por morte, tendo em vista os termos da legislação regente;

d) Foi reconhecida a regularidade da extinção da pensão por morte, tendo em vista os termos da legislação regente;

e) Foi negado a pretensão de escolher o horário das aulas;

f) Não foi acolhida a pretensão de fixar judicialmente os critérios para o custeio do vestibular;

g) Foi mantida a reprovação por faltas na universidade;

h) Foi considerada regular a transferência compulsória do aluno por motivos de comportamento;

i) Foi considerada regular a transferência compulsória do aluno por motivos de comportamento;

j) Foi negada a matrícula em escola técnica por não ter o aluno passado no Vestibulinho;

k) Foi negada a pretensão de obrigar o município a pagar a tarifa integral do transporte para o aluno estudar em Escola Técnica do Estado em outro município, em caso em que o município já pagava metade dos custos. 
Assim, poder-se-ia apontar $100 \%$ não só no reconhecimento da exigibilidade judicial, mas no próprio acolhimento da pretensão de concretização do direito à educação. Talvez isso se deva pela relação que a jurisprudência mantém com a doutrina e pelo fato de esta se apresentar de forma predominante no sentido da exigibilidade do direito à educação.

Um aspecto, contudo, que pode ser levantado como contrário à conclusão da totalidade de atendimento pela Justiça diz respeito à possibilidade de somente casos favoráveis terem apresentado a expressão "direito à educação" na ementa. A propósito, se o critério [NÃO agravo E "direito à educação"] for inserido no campo "pesquisa livre" em vez de na "ementa", o resultado obtido será de 815 julgados (pesquisa feita em $1^{\mathrm{o}} . / 3 / 2015$ no site www.tjsp.jus.br).

Além disso, Adriana Dragone Silveira (2013, p. 381) afirma que haveria julgados que não teriam acolhido o pedido formulado, principalmente em sede de ações coletivas.

Porém, pela leitura dos cinco julgados do Tribunal de Justiça de São Paulo citados no artigo dessa autora, não ficou claro onde estariam as decisões desfavoráveis.

Em relação à Apelação Cível n. 70.606-0 da Câmara Especial, a autora menciona que teria ficado consignado o entendimento de que para o acolhimento do argumento de limitação orçamentária, seria necessário o município comprovar que esgotou as verbas destinadas ao direito.

Sobre a Apelação Cível n. 81.514-0/9-00, da Câmara Especial, a autora afirma que o relator teria entendido que o pedido da ação coletiva deveria ser certo. Não ficou claro se a decisão ao final foi favorável ou não.

No que diz respeito aos Embargos Infringentes n. 82.467-0/2-01, da Câmara Especial, a autora menciona que haveria o entendimento de que a satisfação da decisão judicial deve ocorrer com as receitas já previstas no orçamento ou por meio de créditos adicionais mediante autorização legislativa. Apesar dessa condicionante, não há uma negação peremptória do direito.

Referindo-se à Apelação Cível n. 127.659-0/3-00 da Câmara Especial, o aspecto trazido pela autora seria de que a discricionariedade estaria apenas na forma de satisfazer a obrigação, mas não no seu cumprimento. 
Em referência à Apelação Cível n. 142. 040-0/9-00 da Câmara Especial, Adriana Dragone Silveira destaca que teria havido o entendimento de que a recusa da interferência do judiciário, após reconhecer o direito das crianças, seria negar a própria atividade do Judiciário.

Por fim, tratando da Apelação Cível n. 601.392-5/8-00, da $7^{\mathrm{a}}$ Câmara de Direito Público, segundo a autora, teria havido reconhecimento de que, nos termos da Constituição, não seria possível início de programas ou projetos não incluídos na lei orçamentária, mas nada impediria o Judiciário de determinar que o município incluísse no orçamento as verbas necessárias à instalação de creches e pré-escolas.

Já na tese de Adriana Silveira (2010b, p. 115), nota-se, especificamente sobre o pleito de direito à vaga no ensino infantil, que o $\mathrm{TJ} /$ SP teve posição favorável em 100\% dos casos nos anos de 1999, 2001, 2004, 2006, 2007 e 2008.

Assim, fica aberta a necessidade de prosseguir na pesquisa para confirmar o resultado encontrado, ampliando a amostra de estudo.

\section{ConsideraÇões FinAis}

Parece prevalecer na doutrina o entendimento de que o direito à educação é um direito social de natureza fundamental, exigível judicialmente.

Na busca de entender como esse direito vem sendo concretizado na Justiça do Estado de São Paulo, percebeu-se que, dentro da amostra, entre os assuntos, a demanda por vagas representa 35,92\% dos casos, a de transporte $14,08 \%$, a de matrícula $12,68 \%$ e o questionamento da exigência de idade mínima para cursar a série pretendida responde por $11,27 \%$ dos casos.

Quanto ao problema do sujeito mais acionado na Justiça, do total de 142 casos, apenas 14 foram promovidos em face de particulares, representando o importe de $9,86 \%$, estando todas as demais ações propostas em face do Estado, ou seja, 90,14\%.

Por fim, dentro da amostra, não se constatou posição contrária ao reconhecimento da exigibilidade do direito à educação. Além disso, 
praticamente em todos os casos houve acolhimento do pedido ligado à concretização desse direito. Porém, o efetivo percentual de sucesso necessita de confirmação pelo estudo de uma amostra ampliada, mormente em razão da existência de julgados mencionados na literatura em que não teria havido o acolhimento do pedido.

\section{REFERÊNCIAS}

ARRETCHE, Marta. Democracia, federalismo e centralização no Brasil. Rio de Janeiro: Editora FGV, Editora Fiocruz, 2012.

BARBOSA, Cássio Modenesi; MENEZES, Daniel Francisco Nagao. Jurimetria: buscando um referencial teórico. Revista Intelectus. Ano IX, n. 24, p. 160-185, 2013. Disponível em: <http://www.revistaintellectus.com.br/DownloadArtigo.ashx?codigo=294> Acesso em: $1^{\circ}$. mar. 2015.

BRASIL. Superior Tribunal de Justiça. Habeas-corpus n. 181.636-1, da 6.a Câmara Cível do Tribunal de Justiça do Estado de São Paulo, Brasília, DF, 6 de dezembro de 1994. Lex: jurisprudência do STJ e Tribunais Regionais Federais. São Paulo, v. 10, n. 103, p. 236-240, mar. 1998.

CANOTILHO, José Joaquim Gomes. Direito constitucional, 6. ed. Coimbra: Almedina, 1995.

DUARTE, Clarice Seixas. A educação como um direito fundamental de natureza social. Educ. Soc. Campinas, v. 28, n. 100, out. 2007. Disponível em: $\quad<\mathrm{http}: / /$ www.scielo.br/scielo.php?script=sci_arttext\&pid=S0101$-73302007000300004 \& \operatorname{lng}=$ en\&nrm=iso $>$. Acesso em 26 fev. 2015. $<\mathrm{http} / / /$ dx.doi.org/10.1590/S0101-73302007000300004>.

DUARTE, Clarice Seixas. Direito público subjetivo e políticas educacionais. São Paulo Perspec. São Paulo, v. 18, n. 2, jun. 2004. Disponível em: $\quad<\mathrm{http} / /$ www.scielo.br/scielo.php?script=sci_arttext\&pid=S0102$-88392004000200012 \& \operatorname{lng}=$ en\&nrm=iso $>$. Acesso em 3 mar. 2015. <http:// dx.doi.org/10.1590/S0102-88392004000200012>.

ESTADO DE SÃO PAULO. Tribunal de Justiça do Estado de São Paulo. Sexta Câmara de Direito Público de Férias. Apelação Com Revisão 902242136.1997.8.26.0000. Relator Afonso Faro, julgado em 14/07/1998. 
FERREIRA FILHO, Manoel Gonçalves. Curso de direito constitucional, 36. ed. São Paulo: Saraiva, 2010.

FERREIRA FILHO, Manoel Gonçalves. Aspectos do direito constitucional contemporâneo, 2. ed. São Paulo: Saraiva, 2009, p. 293-306.

FREITAS, Dirce Nei Teixeira de. Ação reguladora da União e qualidade do ensino obrigatório (Brasil, 1988-2007). Educ. rev. Curitiba, n. 31, 2008. Disponível em: $<$ http://www.scielo.br/scielo.php?script=sci_arttext\&pid=S010440602008000100004\&lng=en\&nrm=iso >. Acesso em: 3 mar. 2015. <http:// dx.doi.org/10.1590/S0104-40602008000100004>.

GARCIA, Emerson. O direito à educação e suas perspectivas de efetividade. Justitia. São Paulo, v. 64, n. 197, p. 89-119, jul./dez. 2007, p. 89-119. Disponível em: <http://bdjur.stj.jus.br/dspace/handle/2011/25946>. Acesso em: 4 mar. 2015.

GOMES, Magno Federici. Educação superior privada como serviço de utilidade pública. Ensaio: aval. pol. públ. Educ. Rio de Janeiro, v. 17, n. 63, jun. 2009. Disponível em: <http://www.scielo.br/scielo.php?script=sci arttext\&pid $=\mathrm{S} 0104-40362009000200005 \& \operatorname{lng}=\mathrm{en} \& \mathrm{nrm}=\mathrm{iso}>$. Acesso em 2 mar. 2015. <http://dx.doi.org/10.1590/S0104-40362009000200005>.

INSTITUTO BRASILEIRO DE GEOGRAFIA E ESTATÍSTICA. Censo demográfico 2010: Educação e deslocamento - Resultados da amostra. Rio de Janeiro, 2010, p. 1-205.

INSTITUTO BRASILEIRO DE GEOGRAFIA E ESTATÍSTICA. Estimativas da população residente no Brasil e unidades da federação com data de referência em $1^{\circ}$. de julho de 2016. Disponível em: $<\mathrm{ftp}$ ://ftp.ibge.gov.br/Estimativas_de_Populacao/Estimativas_2016/estimativa_dou_2016_20160913. pdf > Acesso em: 12 abr. 2017.

INSTITUTO NACIONAL DE ESTUDOS E PESQUISAS EDUCACIONAIS. Geografia da Educação Brasileira. Brasília: O Instituto, 2000.

INSTITUTO NACIONAL DE ESTUDOS E PESQUISAS EDUCACIONAIS. Percentual do Investimento Direto em Relação ao PIB por Esfera de Governo, 2011. Disponível em: $<$ http://portal.inep.gov.br/estatisticas-gastoseducacao-indicadores_financeiros-p.t.d._dependencia_administrativa.htm $>$ Acesso em: 5 mar. 2015. 
JACOMINI, Márcia Aparecida. Avaliação da aprendizagem em tempos de progressão continuada: o que mudou? Um estudo de teses e dissertações sobre o tema (2000-2010). Ensaio: aval. pol. públ. Educ. Rio de Janeiro, v. 22, n. 84, set. 2014. Disponível em: <http://www.scielo.br/scielo.php?script=sci_art text\&pid $=\mathrm{S} 010440362014000300010 \& \operatorname{lng}=\mathrm{en} \& \mathrm{nrm}=\mathrm{iso}>$. Acesso em $2 \mathrm{mar}$. 2015. <http://dx.doi.org/10.1590/S0104-40362014000300010>.

OLIVEIRA, Romualdo Portela de. Da universalização do ensino fundamental ao desafio da qualidade: uma análise histórica. Educ. Soc. Campinas, v. 28, n. 100, out. 2007. Disponível em: $<\mathrm{http}: / / w w w . s c i e l o . b r / s c i e l o . p h p ? s c r i p t=s c i$ arttext\&pid=S0101-73302007000300003\&lng=en\&nrm=iso $>$. Acesso em 27 fev. 2015. <http://dx.doi.org/10.1590/S0101-73302007000300003>.

PAROSKI, Mauro Vasni. Do direito fundamental de acesso à Justiça. Scientia Iuris. Londrina, v. 10, p. 225-242, 2006. Disponível em: <http://www.uel.br/ revistas/uel/index.php/iuris/article/view/4132/3546> acesso em: $1^{\circ}$. mar. 2015.

QUEIROZ, Cristina. Direitos fundamentais sociais: questões interpretativas e limites de justiciabilidade. In: SILVA, Virgílio Afonso da (Org.). Interpretação constitucional. São Paulo: Malheiros, 2005, p. 165-216.

SILVA, José Afonso da. Comentário contextual à constituição, 8. ed. São Paulo: Malheiros, 2012.

SILVEIRA, Adriana Dragone. Conflitos e consensos na exigibilidade judicial do direito à educação básica. Educ. Soc. Campinas, v. 34, n. 123, jun. 2013. Disponível em: $<$ http://www.scielo.br/scielo.php?script=sci_arttext\&pid=S0101$-73302013000200003 \& \operatorname{lng}=$ en\&nrm=iso $>$. Acesso em: 2 mar. 2015. $<\mathrm{http} / / /$ dx.doi.org/10.1590/S0101-73302013000200003>.

SILVEIRA, Adriana A. Dragone. A busca pela efetividade do direito à educação: análise da atuação de uma Promotoria de Justiça da Infância e Juventude do interior paulista. Educ. rev. Curitiba, n. esp. 2, 2010a. Disponível em $<$ http://www. scielo.br/scielo.php?script=sci_arttext\&pid=S0104-40602010000500014\&ln $\mathrm{g}=\mathrm{pt \& nrm}=\mathrm{iso}>$. Acesso em 4 mar. 2015. $<\mathrm{http}: / / \mathrm{dx}$.doi.org/10.1590/S010440602010000500014>.

SILVEIRA, Adriana Aparecida Dragone. O direito à educação de crianças e adolescentes: análise da atuação do Tribunal de Justiça de São Paulo (19912008), 2010. Tese (Doutorado em Direito) - Universidade de São Paulo, São Paulo, 2010b. 
ZAMPIRI, Marilene; SOUZA, Ângelo R. O direito ao Ensino Fundamental em uma leitura dos resultados do IDEB e da política educacional em Curitiba-PR. Ensaio: aval. pol. públ. Educ. Rio de Janeiro, v. 22, n. 84, set. 2014. Disponível em: <http://www.scielo.br/scielo.php?script=sci_arttext\&pid=S0104$-40362014000300008 \& \operatorname{lng}=$ en\&nrm=iso $>$. Acesso em: 5 mar. 2015. <http:// dx.doi.org/10.1590/S0104-40362014000300008>.

\section{Dados dos Autores}

\section{Leandro SARai}

Doutorado e Mestrado em Direito Político e Econômico pela Universidade Presbiteriana Mackenzie, MACKENZIE. Especialização em direito empresarial pela Universidade Presbiteriana Mackenzie, MACKENZIE.

E-mail: leandro.sarai@yahoo.com.br.

\section{Daniel Francisco Nagao Menezes}

Especializações em Direito Constitucional e Direito Processual Civil ambos pela PUC-Campinas. Especialização em Didática e Prática Pedagógica no Ensino Superior pelo Centro Universitário Padre Anchieta. Mestre e Doutor em Direito Político e Econômico pela Universidade Presbiteriana Mackenzie. Professor do Programa de Pós-Graduação em Direito Político e Econômico da Faculdade de Direito da Universidade Presbiteriana Mackenzie. Pós-doutorando pela Universidade São Paulo. Membro do CIRIEC-Brasil.

Universidade Presbiteriana Mackenzie (Mackenzie), São Paulo/SP - Brasil.

E-mail: nagao.menezes@gmail.com.

Submetido em: 16-12-2016

Aceito em: 18-05-2017 